\title{
ANALISIS DESAIN PROSES SISTEM PENDINGIN PADA REAKTOR RISET INOVATIF 50 MW
}

\author{
Sukmanto Dibyo, Endiah P.H, Ign. Djoko Irianto \\ Pusat Teknologi dan Keselamatan Reaktor Nuklir BATAN \\ sukdibyo@gmail.com; endiah@batan.go.id; igndjoko@batan.go.id \\ Diterima editor: 15 Januari 2015 \\ Direvisi editor: 11 Februari 2015 \\ Disetujui untuk publikasi: 18 Februari 2015
}

\begin{abstract}
ABSTRAK
ANALISIS DESAIN PROSES SISTEM PENDINGIN PADA REAKTOR RISET INOVATIF 50 MW. Reaktor Riset Inovatif (RRI) merupakan jenis MTR (Material Testing Reactor) yang dipersiapkan ke depan sebagai desain reaktor baru. Daya RRI telah ditetapkan dari perhitungan neutronik dan termohidrolika teras yaitu $50 \mathrm{MW}$ termal. Reaktor bertekanan $8 \mathrm{kgf} / \mathrm{cm}^{2}$ dan laju aliran massa pendingin primer $900 \mathrm{~kg} / \mathrm{s}$. Tantangan yang penting dalam menindak lanjuti desain reaktor ini adalah analisis desain pada sistem pendingin. Makalah ini bertujuan untuk menganalisis desain proses sistem pendingin utama reaktor RRI daya 50 MW (RRI-50) dengan menggunakan program ChemCAD 6.1.4. Dalam analisis ini dilakukan perhitungan neraca massa dan energi (mass/energy balances) pada sistem pendingin primer dan sekunder sebagai pendingin utama. Masing-masing sistem pendingin tersebut terdiri dari 2 jalur beroperasi secara paralel dan 1 jalur redundansi. Disamping itu untuk desain termal unit komponen telah dianalisis dengan program RELAP5, FrenchCreek dan Metoda Analitik. Hasil analisis yang diperoleh adalah desain diagram sistem pendingin yang mencakup data parameter entalpi, temperatur, tekanan dan laju aliran massa pendingin untuk masing-masing jalur. Adapun hasil desain unit komponen utama pada RRI-50 adalah tangki tunda dengan volume 51,5 $\mathrm{m}^{3}, 2$ unit pompa sentrifugal dan 1 unit pompa cadangan pada pendingin primer daya 141 $\mathrm{kW} /$ pompa dan pendingin sekunder daya $206 \mathrm{~kW} /$ pompa, 2 unit penukar panas tipe shell-tube dengan koefisien termal overall $1377 \mathrm{~W} / \mathrm{m}^{2.0} \mathrm{C}$ dan 4 unit menara pendingin yang mampu melepaskan panas ke udara dengan desain temperatur approach $5,0{ }^{\circ} \mathrm{C}$ dan temperatur range $9,0{ }^{\circ} \mathrm{C}$. Desain sistem pendingin reaktor RRI-50 ini telah menetapkan parameter operasi sistem pendingin yaitu temperatur, tekanan dan laju aliran massa pendingin dengan mempertimbangkan tuntutan aspek keselamatan teras reaktor sehingga desain temperatur maksimum pendingin masuk ke teras $44,5{ }^{\circ} \mathrm{C}$.
\end{abstract}

Kata kunci : RRI 50 MW, desain sistem pendingin, program ChemCAD 6.1.4

\begin{abstract}
DESIGN ANALYSIS OF COOLING SYSTEM PROCESS OF THE INNOVATIVE RESEARCH REACTOR $50 \mathrm{MW}$. Innovative Research Reactor RRI is a type of MTR (Material Testing Reactor), which is being prepared in the future as a design of new reactor. The power of RRI has been determined based on the core thermalhydraulic and neutronic calculation, which is $50 \mathrm{MWt}$. The reactor pressure is $8 \mathrm{kgf/ \textrm {cm } ^ { 2 }}$ and coolant mass flow rate is $900 \mathrm{~kg} / \mathrm{s}$. The important challenge in the follow up of this reactor design is the design analysis of cooling system. The purpose of this study is to analyze the design of RRI reactor main coolant system at the power of $50 \mathrm{MWt}(\mathrm{RRI-50)}$ using ChemCAD 6.1.4. In this analysis the mass and energy balances at the primary and secondary cooling system are calculated as main coolant. Each of the cooling system consists of two lines operating in parallel and redundancy lines. Besides that, the thermal design of the component units have been analyzed using RELAP5, FrenchCreek and Analytical Methods. The analyses result obtained is a design of cooling system diagram which includes parameter of enthalpy, temperature, pressure and coolant mass flow rate of each line. Meanwhile, design result of main component unit are delay tank of $51.5 \mathrm{~m}^{3}$ volume, 2 unit centrifugal pumps and 1 unit stand-by pump for the primary coolant pump each of $141 \mathrm{~kW}$ power and secondary coolant pump each of $206 \mathrm{~kW}$ power, 2 unit of shell-tube heat exchanger with overall thermal coefficient of $1377 \mathrm{~W} / \mathrm{m}^{2 . o} \mathrm{C}$ and 4 unit cooling tower that capable to release the heat to the air at approach temperature of $5,0^{\circ} \mathrm{C}$ and range temperature of $9,0^{\circ} \mathrm{C}$. Design of reactor coolant system RRI-50 has decided the operating parameters of cooling system are temperature, pressure and mass flow rate by considering into the demands of the safety aspects of the reactor core therefore design of maximum coolant temperature to the reactor core is $44,5^{\circ} \mathrm{C}$.
\end{abstract}

Keywords : RRI 50MW, design of cooling system, program ChemCAD 6.1.4. 


\section{PENDAHULUAN}

Reaktor riset merupakan fasilitas nuklir yang penting untuk melakukan kegiatan penelitian dan produksi isotop, oleh karena itu dalam rangka mewujudkan desain reaktor riset ke depan perlu dipersiapkan desain reaktor baru yang dalam hal ini adalah reaktor riset inovatif (RRI). Pada mulanya desain reaktor RRI telah didesain pada daya 20MW[1], kemudian berdasarkan pertimbangan desain neutronik dan termohidrolika teras reaktor maka ditetapkan hasil desain konseptual reaktor riset berdaya $50 \mathrm{MWt}$ bertekanan $8 \mathrm{kgf} / \mathrm{cm}^{2}$ (sesuai dengan hasil analisis desain termohidrolika teras RRI50). Dari berbagai opsi konfigurasi teras setimbang maka desain neutronik teras alternatif terbaik reaktor RRI yaitu berbahan bakar $\mathrm{U}_{9} \mathrm{Mo}-\mathrm{Al}$ dengan tingkat muat ${ }^{235} \mathrm{U}$ sebesar 400 gr panjang aktif bahan bakar $70 \mathrm{~cm}$ [2]. Begitu pula desain termohidrolika teras, untuk memenuhi kriteria marjin keselamatan teras terpenuhi maka hasil analisis menunjukkan bahwa reaktor memiliki daya termal 50 MW bertekanan sekitar $8 \mathrm{kgf} / \mathrm{cm}^{2}$ dan dioperasikan dengan laju aliran massa pendingin sebesar 900 $\mathrm{kg} / \mathrm{s}[3]$.

Dalam desain reaktor riset inovatif $50 \mathrm{MWt}$ (RRI-50) maka penelitian ini menganalisis desain sistem pendinginnya. Desain ini merupakan pendukung pada pelaksanaan desain konseptual reaktor RRI-50 secara keseluruhan. Berdasarkan tingkat daya maka RRI-50 merupakan jenis reaktor riset daya tinggi yang harus menggunakan moda pendinginan konveksi paksa pada teras reaktor. Merujuk pada beberapa reaktor riset, secara umum bahwa sistem pendingin reaktor riset meliputi komponen utama yaitu teras reaktor di dalam bejana reaktor, pompa sirkulasi sistem pendingin primer dan sekunder, penukar panas, tangki tunda N-16 dan menara pendingin (cooling tower) $[4,5,6,7]$. Sistem lain yang juga terdapat pada reaktor dan tidak tercakup dalam desain ini adalah fasilitas iradiasi, sistem reflektor, sistem pendingin untuk keselamatan darurat reaktor, sistem pemurnian pendingin, sistem make-up pendingin dan sistem bantu.

Desain sistem pendingin merupakan tantangan yang penting dalam menindak-lanjuti desain reaktor. Dalam desain sistem pendingin, diperlukan analisis termodinamika untuk mendapatkan data proses transfer massa dan energi (entalpi) fluida dengan mengacu pada ketetapan kesetimbangan massa dan panas (mass and heat balance). Pembuatan diagram aliran proses (flow-sheet) merupakan langkah desain pada tahap pertama, selanjutnya ditetapkan dan dihitung kondisi parameter proses pendingin (laju aliran sistem pendingin dan neraca panas) sesuai desain/rencana yang akan dikondisikan. Pada tahap ini, perhitungan desain parameter operasi didasarkan pada desain diagram alir proses yang menggunakan program ChemCAD 6.1.4, dimana program ChemCAD ini adalah program komputer yang dapat digunakan untuk melakukan desain operasi, evaluasi dalam industri pada proses equipment manufacturing, analisis sistem operasi unit (unit operation) instalasi proses termasuk melakukan desain baru (equipment sizing) pada sistem pendinginan [8]. Program ChemCAD telah berhasil diaplikasikan dalam desain sistem pendingin reaktor riset OPAL 20 MWt Australia [5]. Di samping itu, program ini memuat data pustaka unit komponen yang cukup lengkap seperti pompa, penukar panas, katup, menara pendingin, vessel, kompresor dan sebagainya.

Pengambilan panas dari reaktor merupakan fungsi utama sistem pendingin sehingga tidak terjadi pendidihan di lokasi manapun di teras reaktor. Oleh karena itu, untuk pertimbangan aspek keselamatan supaya reaktor dapat dioperasikan dengan aman, maka sistem pendingin primer dan pendingin sekunder tersusun dalam 2 jalur sistem pendingin yang didukung dengan tambahan satu jalur cadangan (redundansi).

Tujuan dari makalah ini adalah menganalisis desain sistem pendingin primer dan sekunder sebagai pendingin utama reaktor RRI-50 dengan menggunakan program ChemCAD6.1.4, menentukan parameter-parameter operasinya berdasarkan desain diagram alir sistem pendingin utama serta dilengkapi dengan desain awal unit komponen sehingga reaktor dapat beroperasi dalam kondisi aman.

\section{TEORI}

\section{Desain Sistem Pendingin}

Reaktor RRI-50 seperti halnya riset jenis MTR (Material Test Reactor), secara umum dilengkapi dengan sistem pendingin primer dan pendingin sekunder. Masing-masing sistem pendingin utama terdiri dari 2 modul jalur dan 1 jalur redundansi dilengkapi dengan pompa-pompa sirkulasi yang 
beroperasi secara paralel untuk mengoperasikan pendinginan paksa pada teras reaktor. Adapun unit komponen utama sistem pendingin reaktor meliputi bejana reaktor, tangki tunda $\mathrm{N}-16$, pompa, penukar panas, dan menara pendingin. Subsistem yang tidak dibahas dalam desain sistem utama pendingin reaktor ini diantaranya sistem pemurnian air, sistem penyimpan elemen bakar, sistem reflektor $\mathrm{D}_{2} \mathrm{O}$, sistem pendinginan darurat, sistem make-up pendingin sekunder dan sistem bantu lainnya, temperatur, tekanan dan laju aliran massa pendingin dengan mempertimbangkan tuntutan aspek keselamatan teras reaktor sehingga temperatur pendingin masuk ke teras tidak lebih dari $44,5{ }^{\circ} \mathrm{C}$ [3].

Pada prinsipnya peran penting sistem pendingin reaktor adalah untuk mengambil panas yang dibangkitkan dari reaksi fisi di teras reaktor. Setelah meninggalkan teras reaktor, air pendingin menuju tangki tunda $\mathrm{N}-16$ (decay tank $\mathrm{N}-16$ ). Melalui jalur percabangan, pendingin mengalir menuju pompa sentrifugal. Setiap discharge pompa masing-masing dihubungkan ke unit penukar panas (sebagai sistem interface), di dalam unit ini panas ditransfer ke sistem pendingin sekunder yang dilengkapi dengan menara pendingin. Melalui menara pendingin ini panas dikeluarkan ke udara atmosfer. Untuk pendingin cadangan dapat dipasang secara paralel sebagai sistem pendingin stand-by. Sistem pendingin primer adalah untai tertutup dimana reaktor bertekanan sekitar $8 \mathrm{kgf} / \mathrm{cm}^{2}$.

Gambar 1 menunjukkan desain konseptual diagram aliran sistem pendingin RRI. Secara umum terdapat 4 jalur aliran pendingin (stream) yakni jalur pendingin primer ke reaktor, jalur pendingin primer dari reaktor, jalur pendingin sekunder ke alat penukar panas, dan jalur pendingin sekunder menuju menara pendingin

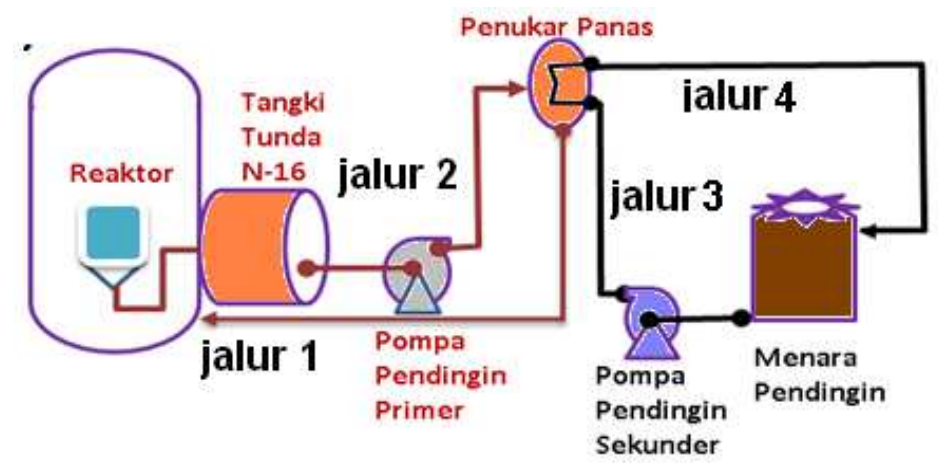

Keterangan :

jalur 1 : Pendingin primer ke reaktor.

jalur 2 : Pendingin primer dari reaktor.

jalur 3 : Pendingin sekunder ke penukar panas.

jalur 4 : Pendingin sekunder menuju menara pendingin.

\section{Gambar 1. Skematika diagram alir utama sistem pendingin}

Desain diagram proses ini menetapkan laju alir pendingin, temperatur pendingin masuk ke reaktor, temperatur dan tekanan reaktor yang diperlukan untuk menjaga integritas teras reaktor melalui pengambilan panas oleh sistem pendingin. Hasil desain dasar yang diperoleh berupa diagram proses aliran pendingin berdasarkan daya reaktor. Parameter termohidrolika teras, diperlukan sebagai input untuk perhitungan neraca panas dan massa sistem pendingin reaktor. Hal ini dimaksudkan untuk memperoleh diagram proses aliran dan watak sistem untai (circuit system behaviour) menggunakan program ChemCAD.

\section{Desain Unit Komponen}

Unit komponen utama sistem pendingin reaktor diantaranya adalah pompa, penukar panas, dan menara pendingin. Pada bagian sistem pendingin reaktor primer, dilengkapi dengan tangki tunda N-16 yang berada di sisi hisap (suction line) pompa. Tangki tunda ini merupakan salah satu bagian dari sistem jaringan pendingin yang berfungsi untuk meluruhkan radiasi produk isotop radioaktif Nitrogen16 dari reaktor.

Pompa adalah unit komponen yang berfungsi untuk mengambil panas dari teras reaktor melalui sirkulasi air pendingin. Pompa sentrifugal merupakan jenis pompa yang paling banyak digunakan di 
dunia karena memiliki kontinuitas aliran yang stabil. Ada berbagai jenis pompa sentrifugal dikelompokkan berdasarkan pada variasi prinsip kerjanya. Pompa ini, memiliki prinsip kerja cukup sederhana, teruji, efektifdan relatif efisien. Kenaikan tekanan aliran diperoleh dari energi mekanik dari putaran poros (shaft) ke fluida melalui putaran impeler. Pompa harus mengatasi hambatan aliran berupa perbedaan tekanan, perbedaan ketinggian dan friksi. Gambar 2 menunjukkan diagram skematik pompa sentrifugal [9].

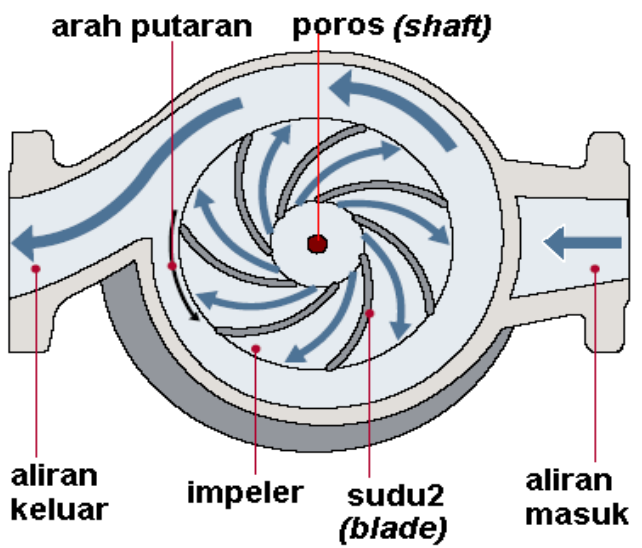

Gambar 2. Diagram pompa sentrifugal[9]

Untuk mentransfer panas dari sirkulasi sistem pendingin primer ke sistem pendingin sekunder, digunakan unit komponen penukar panas. Penggunaan jenis shell-tube dapat dipilih dengan pertimbangan memiliki kapasitas transfer panas yang besar, banyak digunakan secara luas, mudah perawatan, data informasi yang lengkap untuk desain dan banyak keuntungan dibanding tipe lainnya.

Desain penukar panas dilakukan dengan metoda analitik untuk memperoleh parameter desain termal sesuai dengan data dari desain diagram proses sistem pendingin yang diperlukan pada RRI-50. Metoda ini menggunakan persamaan neraca massa, energi dan persamaan konstitutif yang sudah baku. Hasil perhitungan dikerjakan secara iteratif antara energi panas (Q), temperatur fluida (T) dan aliran massa fluida dari alat penukar panas. Pada kondisi normal, sistem aliran pendingin beroperasi pada kecepatan dan laju aliran pendingin konstan. Persamaan transfer panas $(\mathrm{Q})$ dari pendingin primer ke sekunder yang berlaku secara umum adalah sebagai berikut [10,11]:

$$
\begin{gathered}
d Q=w . C p \cdot d T \\
d Q=U \cdot A \cdot \Delta T_{L M T D}
\end{gathered}
$$

dengan,

$\begin{array}{lll}w & : & \text { aliran massa pendingin }(\mathrm{kg} / \mathrm{s}) \\ C p & : & \text { panas spesifik (Joule/kg.K) } \\ d T & : & \text { beda temperatur pendingin masuk dengan keluar teras }(\mathrm{K}) \\ U & : & \text { koef. transfer panas }\left(\mathrm{Joule} / \mathrm{s} . \mathrm{m}^{2} . \mathrm{K}\right) \\ A & : & \text { luasan }\left(\mathrm{m}^{2}\right) \\ \Delta T_{\text {LMTD }} & : & \text { beda temperatur logaritmik }(\mathrm{K})\end{array}$

Pada bagian sistem pendingin sekunder, unit komponen yang digunakan untuk melepaskan panas ke udara luar adalah menara pendingin, melalui pendinginan ini, panas dilepas ke udara yang temperaturnya lebih rendah secara transfer panas latent dan sensible. Pendinginan disertai dengan hilangnya sebagian kecil percikan air (drift loss) dan penguapan yang ditransfer ke udara. Jumlah percikan air yang hilang ini dalam literatur pada umumnya pada rentang $0.0118 \%$ sampai $0.161 \%$ [12]. Menara pendingin dilengkapi dengan filler sebagai mediator antara udara dengan air hangat dari penukar panas. Fungsi dari filler ini juga untuk menaikkan luas permukaan kontak dan penyebaran yang lebih baik [13].

Pada sistem menara pendingin ini, air hangat disebarkan (sprayed) pada bagian atas dengan menggunakan nosel distribusi. Di bagian bawah terdapat penampungan (basin) yang dilengkapi 
dengan fasilitas katup blow-down dan sistem make-up water. Menara pendingin yang dipilih untuk sistem pendingin sekunder adalah jenis induced draft tower. Jenis ini banyak digunakan dalam sistem pendingin dan dilengkapi dengan kipas yang terletak pada sisi discharge untuk menarik udara supaya melewati menara sebagaimana ditunjukkan pada Gambar 3. Tarikan kipas juga mempengaruhi udara yang mengandung butiran air keluar ke discharge.

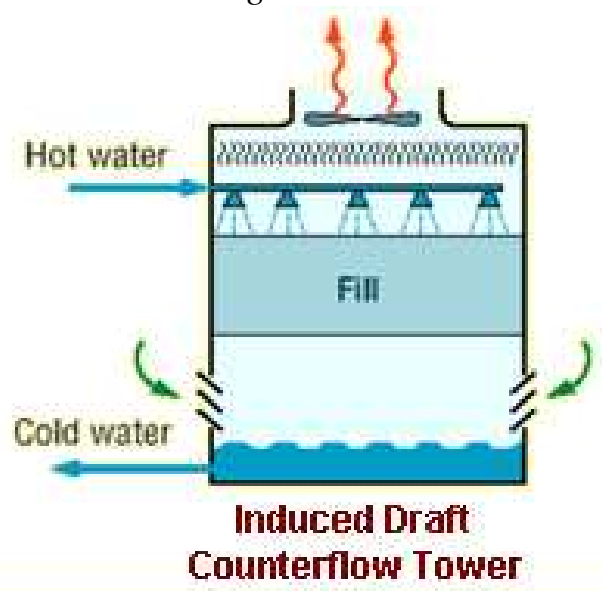

Gambar 3. Skematika induced draft counterflow tower [14]

Pendinginan berlangsung melalui transfer panas antara udara dan air yang masuk menara pendingin. Sementara itu, temperatur approach (beda temperatur antara air keluar menara pendingin dengan temperatur udara wet-bulb) adalah sekitar $5{ }^{\circ} \mathrm{C}$. Teori yang paling umum dalam proses transfer panas dikembangkan oleh Merkel. Analisis ini merupakan karakteristik menara yang didasarkan pada beda entalpi sebagai driving force sebagai berikut [14];

$$
\frac{K a V}{L}=\int_{T 2}^{T 1} \frac{d T}{h^{\prime}-h}
$$

dengan,

$K \quad: \quad$ koefisien transfer massa $\left(\mathrm{kg}\right.$ air $\left./ \mathrm{s}^{2} \mathrm{~m}^{2}\right)$

$a \quad: \quad$ area kontak $\left(\mathrm{m}^{2}\right) /$ volume menara $\left(\mathrm{m}^{3}\right)$

$V \quad: \quad$ volume menara $\left(\mathrm{m}^{3}\right) /$ area $\left(\mathrm{m}^{2}\right)$

$L \quad: \quad$ laju massa air pendingin dalam penampang menara $\left(\mathrm{kg} / \mathrm{s} \cdot \mathrm{m}^{2}\right)$

$h, h \quad: \quad$ entalpi udara jenuh pada temperatur air dan entalpi aliran udara (Joule/kg)

Menara pendingin Mechanical-draft pada umumnya dirancang pada rentang rasio L/G dari 0,75 sampai 1,50, kemudian nilai $K a V / L$ bervariasi dari 0,50 sampai 2,50 [15]. L/G adalah rasio antara laju massa air pendingin dengan laju massa udara menara pendingin. Dalam penentuan desain menara pendingin, ukuran menara yang dibutuhkan berdasarkan data temperatur approach, cooling range dan wet bulb, laju aliran massa pendingin, laju udara yang melalui menara.

\section{METODOLOGI}

Untuk mendapatkan desain proses pendinginan reaktor dengan menggunakan ChemCAD 6.1.4 maka diperlukan sistematika tata kerja sebagaimana ditunjukkan pada skema diagram Gambar 4, 


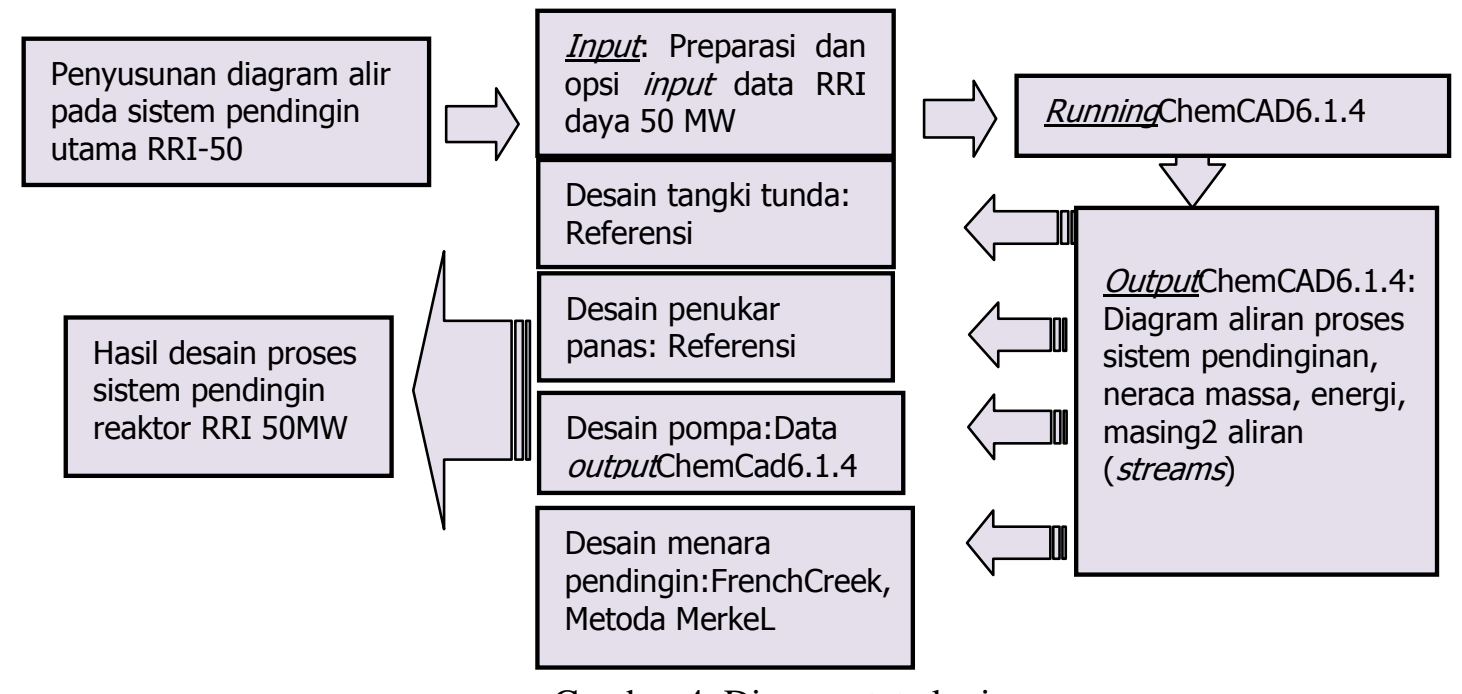

Gambar 4. Diagram tata kerja

Tahap pertama dalam metodologi desain ini adalah membuat diagram aliran sistem pendingin yang mengacu pada desain-desain sistem pendingin reaktor riset $[1,4,7]$. Desain parameter sistem pendingin RRI-50 dianalisis dengan menggunakan program ChemCAD 6.1.4. Berdasarkan desain diagram aliran untuk proses pendinginan maka diperoleh hasil perhitungan neraca massa dan neraca panas pada setiap jalur aliran. Neraca massa dan neraca panas ini sebagai hukum kekekalan massa dan energi yang merupakan perhitungan kuantitatif dari aliran pendingin pada kondisi tunak (steady-state) $[1,8]$. Prinsip inilah mendasari program ChemCAD menghitung desain sistem proses pendingin. Adapun output ChemCAD diacu untuk perhitungan desain unit-unit komponen utama sistem pendingin.

Sebelum menganalisis desain parameter sistem pendingin, maka perlu ditentukan beberapa ketetapan dan parameter input sistem pendingin yaitu sebagai berikut :

- Daya yang dibangkitkan dari reaktor adalah $50 \mathrm{MW}$ termal.

- Laju aliran massa nominal pendingin primer $=900 \mathrm{~kg} / \mathrm{s}$.

- $\quad$ Temperatur pendingin masuk teras $=44,5^{\circ} \mathrm{C}$.

- Temperatur wet-bulb udara $=28,0^{\circ} \mathrm{C}$.

- Sistem pendingin dihitung pada kondisi adiabatik, di mana pada jalur aliran pendingin tidak ada panas yang diserap dari udara ataupun yang lepas ke udara. Panas yang dibangkitkan oleh reaktor hanya dilepas melalui menara pendingin.

\section{HASIL DAN PEMBAHASAN}

\section{Desain Sistem Pendinginan}

Hasil desain sistem pendingin RRI untuk daya reaktor 50MW meliputi data parameter operasi sistem pendingin yaitu temperatur, tekanan dan laju aliran massa pendingin untuk masing-masing jalur, begitu pula data desain untuk unit komponen pada sistem pendingin primer dan sekunder. Gambar 5 menunjukkan desain diagram alir proses sistem pendingin primer dan sekunder reaktor RRI50 yang disusun dengan menggunakan paket program ChemCAD6.1.4. Sebagaimana ditunjukkan pada Gambar tersebut, diagram ini terdapat 2 jalur sistem pendingin dilengkapi dengan 2 unit komponen penukar panas dan 4 unit menara pendingin. Disamping itu, desain pendingin reaktor RRI50 juga didukung dengan tambahan satu jalur cadangan sebagai redundant cooling systems back-up sebagaimana seperti pada desain sistem pendingin reaktor riset daya tinggi. Jalur cadangan reaktor RRI-50 memiliki satu unit penukar panas dan 2 unit menara pendingin. Dalam perhitungan desain ini, jalur cadangan disimulasikan tanpa laju aliran yang diatur oleh moda splite (percabangan) pada program ChemCAD 6.1.4. 


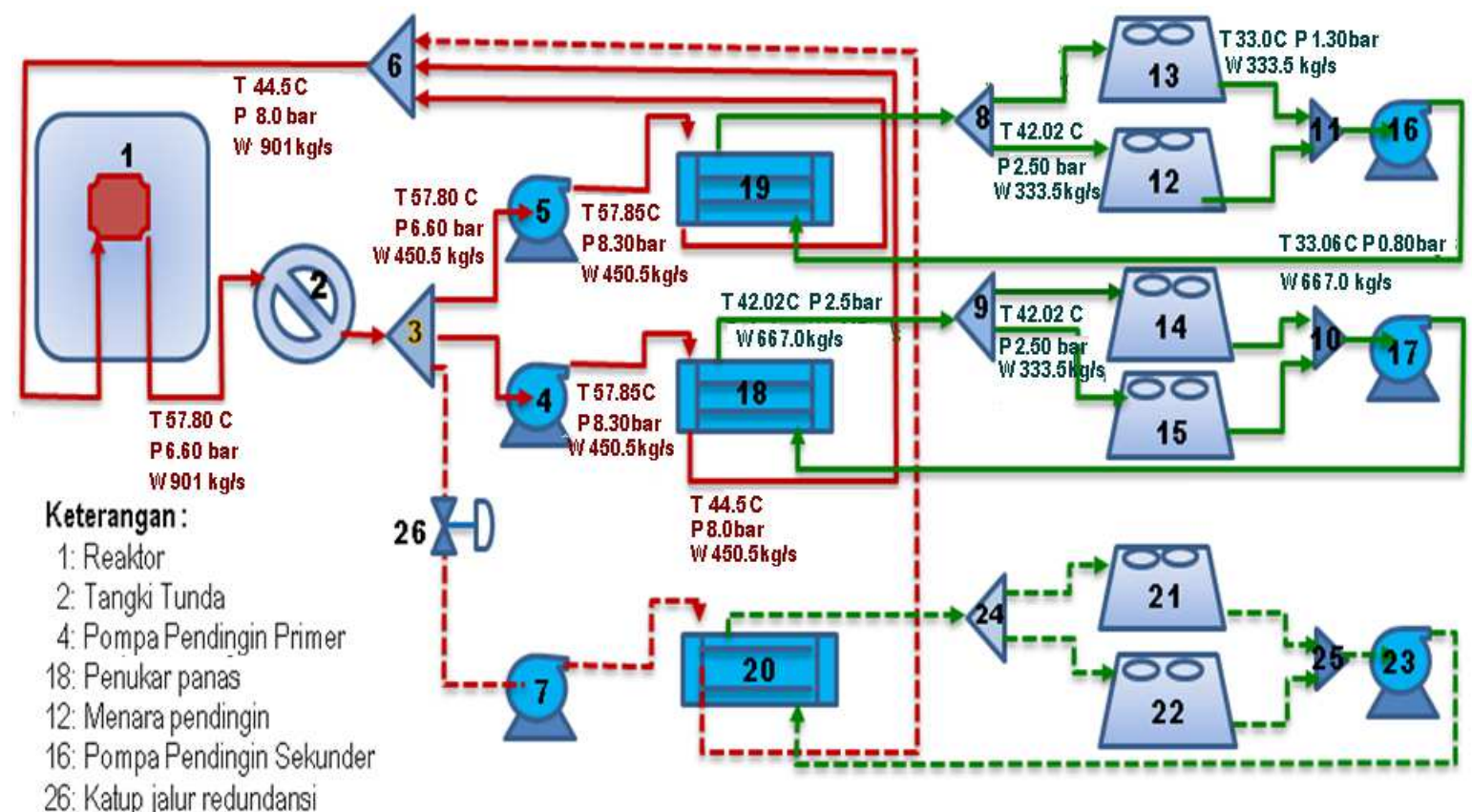

Gambar 5. Desain diagram alir proses sistem pendingin primer dan sekunder RRI-50

Hasil perhitungan desain proses ini diperoleh dengan menggunakan metodologi seperti yang ditunjukkan pada diagram tata kerja (Gambar 4). Dalam desain ini, diagram sistem pendingin hanya dititik-beratkan pada jalur utama sistem pendingin saja, sehingga belum melibatkan sub-sistem pendingin reaktor.

Tabel 1 merupakan hasil kompilasi parameter temperatur, laju aliran massa pendingin dan beban panas pada unit komponen sistem pendingin RRI-50, yang menunjukkan bahwa sistem pendingin telah sesuai dengan kondisi desain yang ditentukan setelah melalui perhitungan justifikasi neraca massa dan energi oleh program ChemCAD 6.4.1. Dari hasil perhitungan dengan menggunakan program tersebut maka beban energi panas yang dibangkitkan dari reaktor adalah 50,06 MJoule/s (heat source) dapat dilepaskan/dibuang oleh menara pendingin sebesar 50,32 MJoule/s (heat sink). Dalam hal ini ada panas tambahan yang dihitung oleh ChemCAD 6.4.1 yaitu 0,262 MJoule/s yang berasal dari putaran pompa-pompa sirkulasi. Begitu pula laju aliran massa pendingin primer menghasilkan angka $901 \mathrm{~kg} / \mathrm{s}$ sehingga untuk satu jalur pendingin primer sebesar 450,5 kg/s. Adapun untuk laju aliran massa satu jalur pendingin sekunder adalah $333,5 \mathrm{~kg} / \mathrm{s}$. Dengan demikian, hal yang penting dalam desain sistem pendingin ini adalah tuntutan aspek keselamatan teras reaktor yang menetapkan temperatur pendingin masuk ke teras tidak lebih dari $44,5^{\circ} \mathrm{C}$ sehingga tidak terjadi pendidihan inti pada titik terpanas dan keselamatan termohidrolika teras terpenuhi [3].

Oleh karena pembuatan desain proses sistem pendingin ini menggunakan program ChemCAD maka untuk memperoleh konvergensi perhitungan perlu ditetapkan dengan benar data input awal pada setiap jalur pendingin terhadap parameter operasi temperatur, tekanan dan laju aliran massa. Dengan demikian dapat terpenuhi desain sistem pendingin pada daya reaktor, laju aliran massa pendingin dan temperatur pendingin yang masuk ke teras reaktor sesuai dengan yang direncanakan.

Tabel 1. Hasil desain temperatur dan laju aliran massa sistem pendingin

\begin{tabular}{|l|c|c|c|c|c|c|c|}
\hline & Reaktor & \multicolumn{2}{|c|}{ Penukar panas } & \multicolumn{4}{c|}{ Menara pendingin } \\
\hline No. Unitkomponen : & 1 & 18 & 19 & 12 & 13 & 14 & 15 \\
\hline $\begin{array}{l}\text { Aliran massa pendingin primer } \\
\text { kg/s }\end{array}$ & 901,0 & 450,5 & 450,5 & & & & \\
\hline $\begin{array}{l}\text { Aliran massa pendingin } \\
\text { sekunder kg/s }\end{array}$ & & 667,0 & 667,0 & 333,5 & 333,5 & 333,5 & 333,5 \\
\hline Temperatur pendingin primer & 44,50 & 57,85 & 57,85 & & & & \\
\hline Masuk, ${ }^{\circ} \mathrm{C}$ &
\end{tabular}




\begin{tabular}{|l|c|c|c|c|c|c|c|}
\hline Keluar, ${ }^{\circ} \mathrm{C}$ & 57,80 & 44,60 & 44,60 & & & & \\
\hline Temperatur pendingin sekunder & & 33,05 & 33,05 & 42,02 & 42,02 & 42,02 & 42,02 \\
\hline Masuk, ${ }^{\circ} \mathrm{C}$ & & 42,02 & 42,02 & 33,00 & 33,00 & 33,00 & 33,00 \\
\hline Keluar, ${ }^{\circ} \mathrm{C}$ & & & & & \\
\hline
\end{tabular}

${ }^{*}$ MJoule/s = Mwatt

\section{Desain Unit Komponen}

Pada sistem pendingin RRI-50, terdapat unit komponen tangki tunda N-16 (nomor 2), pompa sirkulasi sistem pendingin primer dan sekunder (nomor 4, 5, 16, 17, 23), alat penukar panas (nomor 18, 19) dan menara pendingin (nomor 12, 13, 14, 15) yang beroperasi dalam 2 jalur sistem pendingin. Adapun jalur pendingin cadangan sebagai sistem redundansi juga dilengkapi dengan unit pompa (nomor 7) penukar panas (nomor 20) dan menara pendingin (nomor 21, 22), akan tetapi pada prinsipnya jalur ini juga diintegrasikan dengan jalur lainnya melalui pengaturan katup yang diilustrasikan oleh katup nomor 26. Desain unit-unit komponen yang ditambahkan dalam analisis desain ini merupakan kelengkapan untuk menghasilkan suatu desain yang lebih konprehensif pada sistem pendingin utama RRI-50.

Desain unit tangki tunda dikonsep berbentuk silinder yang dipartisi oleh penyekat menjadi 4 aliran di dalamnya, bentuk tangki ini mengacu pada tangki tunda reaktor JRR3M Jepang yang merupakan salah satu contoh tangki tunda yang berhasil dioperasikan dengan handal. Konsep model desain tangki tunda RRI-50 didesain dengan bantuan RELAP5. Pada dasarnya desain tangki tunda ini adalah mengetahui waktu tempuh aliran pendingin dari nosel aliran masuk sampai keluar tangki. Gambar model desain tangki tunda ditunjukkan pada Gambar 6 [16]. Mengacu model desain tersebut, diperoleh data hasil desain yang disampaikan pada Tabel 2.

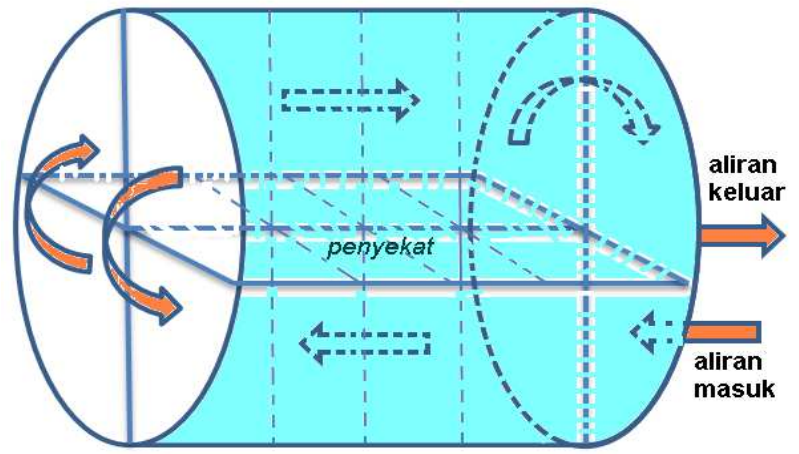

Gambar 6. Model desain tangki tunda N-16 [16]

Tabel 2. Data desain dasar tangki tunda sistem pendingin RRI-50

\begin{tabular}{|c|l|c|}
\hline No & Parameter Desain & Besaran \\
\hline 1 & Laju aliran massa pendingin $(\mathrm{kg} / \mathrm{s})$ & 900 \\
\hline 2 & Diameter $(\mathrm{m})$ & 2,7 \\
\hline 3 & Panjang $(\mathrm{m})$ & 8,1 \\
\hline 4 & Volume total $\left(\mathrm{m}^{3}\right)$ & 51,504 \\
\hline 5 & Diameter nosel $(\mathrm{m})$ & 0,81 \\
\hline 6 & Waktu tempuh (sekon) & 60 \\
\hline
\end{tabular}

\section{Desain Pompa Sirkulasi}

Data utama desain pompa sirkulasi untuk pendingin primer dan sekunder telah diperoleh seperti ditunjukkan pada Tabel 3. Data awal spesifikasi pompa dapat diperoleh dari menu spec sheet report dari program ChemCAD. Data input program yang dipakai untuk desain adalah temperatur aliran, laju aliran massa, efisiensi dan menggunakan specify outlet pressure sebagai mode operasi pompa. Pompa ini ditentukan jenis sentrifugal single stage di mana pompa pendingin primer dan pompa pendingin sekunder memiliki kapasitas yang berbeda sesuai dengan kondisi operasi dan laju aliran pendingin 
yang harus disirkulasikan. Tiga unit pompa pendingin primer memiliki jenis dan kapasitas yang sama. Dua unit pompa secara paralel dioperasikan selama operasi normal, adapun pompa ketiga adalah sebagai pompa cadangan (on stand-by). Masing-masing pompa pendingin primer dilengkapi dengan fly wheel untuk meningkatkan waktu coast-down flow.

Tabel 3 Data desain pompa primer dan pompa sekunder

\begin{tabular}{|l|c|c|}
\hline \multicolumn{1}{|c|}{ Parameter } & Pompa primer & Pompa sekunder \\
\hline Desain temperatur, ${ }^{\circ} \mathrm{C}$ & 60 & 60 \\
\hline Tipe & Sentrifugal, single stage & Sentrifugal, single stage \\
\hline Laju aliran massa pompa sirkulasi, kg/s & 901 & 1334 \\
\hline Head pompa, $\mathrm{m}$ & 20,72 & 20,51 \\
\hline Daya pompa, $\mathrm{kW}$ & 141 & 206 \\
\hline NPSHa, $\mathrm{m}$ & 66 & 7,7 \\
\hline RPM pompa & 3550 & 3550 \\
\hline Efisiensi pompa, $\%$ & 0,80 & 0,80 \\
\hline
\end{tabular}

\section{Desain Penukar Panas}

Data desain termal penukar panas pada sistem pendingin RRI-50 telah diperoleh yaitu data temperatur, tekanan dan laju aliran massa pendingin, beban panas dan spesifikasi (dimensi) penukar panas. Proses desain termal penukar panas pada dasarnya adalah menghitung koefisien transfer panas dari fluida panas ke fluida pendingin, luasan transfer panas yang diperlukan dan rugi tekanan aliran yang ditentukan.

Penukar panas RRI-50 memiliki kapasitas 25,03 MJoule/s, data temperatur dan laju aliran pendingin yang diperoleh dari hasil perhitungan menggunakan ChemCad 6.4.1. Untuk itu terdapat 2 unit penukar panas yang mampu pada kondisi steady memindahkan beban panas 50 MJoule/s dari reaktor, begitu pula 1 unit penukar panas yang dipasang pada jalur redundansi memiliki data desain yang sama. Model dan tipe penukar panas adalah shell-tube 1-2 pass dilengkapi dengan 6 buah baffle pengarah aliran [17].

\section{Desain Menara Pendingin}

Hasil perhitungan desain termal pada menara pendingin sistem pendingin sekunder disajikan pada Tabel 5 yang mencakup data spesifikasi desain dasar pada menara pendingin. Desain ini menggunakan data masukan dari desain sistem pendingin reaktor sebagaimana disampaikan pada Tabel 1. Terdapat 4 unit menara pendingin dan 1 unit cadangan yang masing-masing memiliki kemampuan beban 12,58 MJoule/s. Desain menara pendingin telah ditentukan jenis induced draft tower, di mana penggunaan jenis ini dilengkapi dengan kipas untuk menarik udara sehingga melewati butiran air pendingin dari atas menara. Temperatur air keluar dari menara pendingin dipengaruhi oleh kecepatan udara dan laju massa air panas yang dilepas ke udara.

Sumber air make-up diperlukan untuk mengisi kembali volume air yang hilang akibat percikan 0,02\% [14], evaporasi dan laju blowdown. Dalam analisis ini Cyclus Ratio (CR) yaitu rasio mineral terlarut antara air pendingin dengan air make-up adalah 4,7 (dengan asumsi laju penguapan dan kualitas air make-up tidak berbeda dengan kondisi sistem pendingin sekunder RSG-GAS maka digunakan pendekatan kesetaraan dengan RSG-GAS) [18]. Sementara itu laju aliran pendingin adalah $333,5 \mathrm{~kg} / \mathrm{s}$. Berdasarkan data masukan tersebut maka desain menara pendingin dianalisis dengan menggunakan FrenchCreek software sebagaimana data hasil keluaran yang ditunjukkan pada Gambar 7 [19]. Desain termal dan karakteristik menara pendingin disajikan pada Tabel 5. 


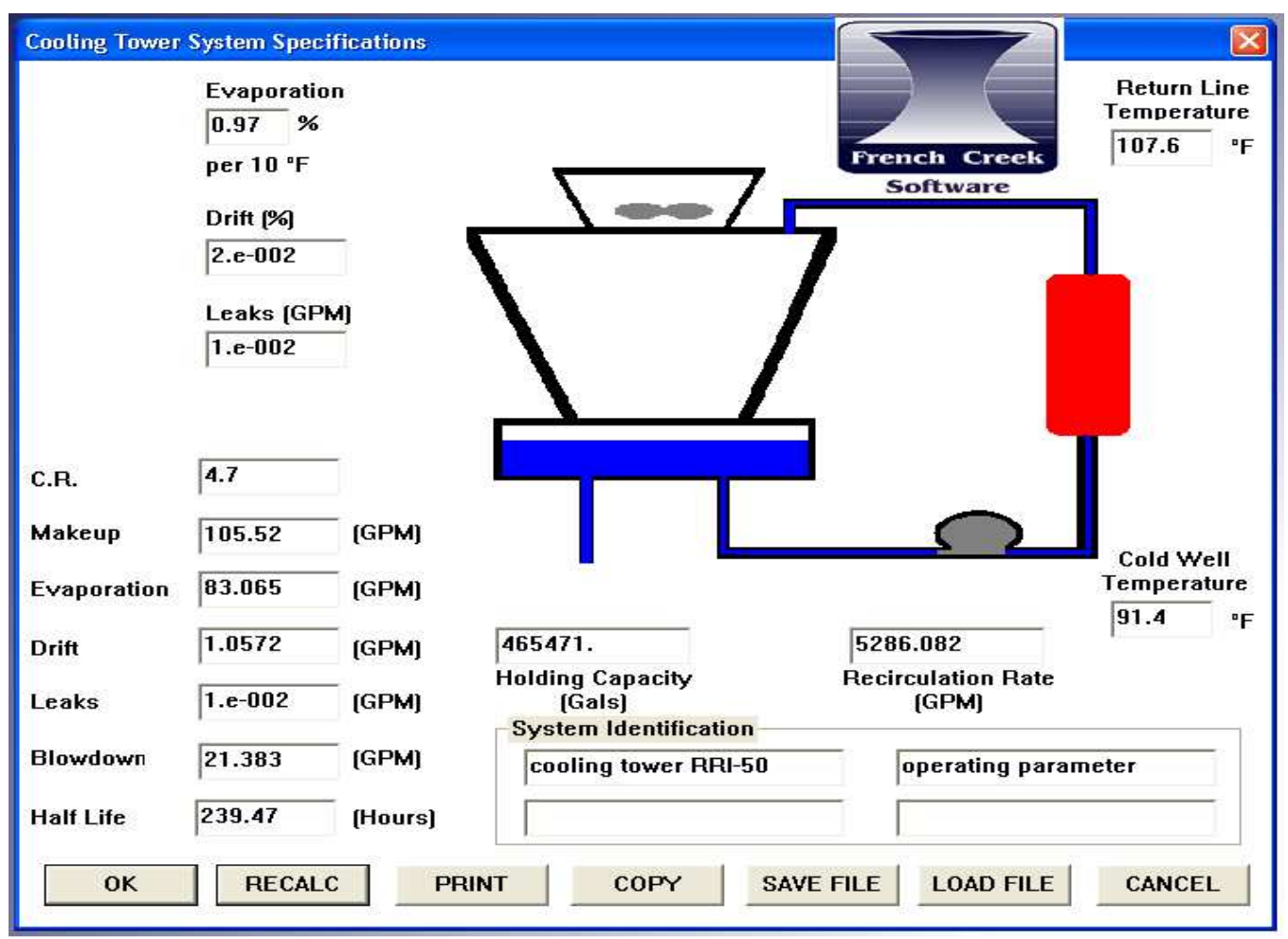

Gambar 7. Output tampilan FrenchCreek software menara pendingin RRI-50

Tabel 5 Data desain menara pendingin

\begin{tabular}{|r|l|c|}
\hline No & Parameter & Besaran \\
\hline \hline 1 & Jenis / tipe & Induced draft \\
\hline 2 & Beban desain termal per unit, MJoule/s & 12,58 \\
\hline 3 & Jumlah unit total, - & 5 \\
\hline 4 & Laju massa pendingin/unit, kg/s & 333,5 \\
\hline 5 & $\begin{array}{l}\text { Rasio laju massa air/Laju massa udara } \\
(\text { L/G) }\end{array}$ & 1,125 \\
\hline 5 & Temperatur air masuk, ${ }^{\circ} \mathrm{C}$ & 42,0 \\
\hline 6 & Temperatur air keluar, ${ }^{\circ} \mathrm{C}$ & 33,0 \\
\hline 7 & Temperatur approach, ${ }^{\circ} \mathrm{C}$ & 5,0 \\
\hline 8 & Temperatur range, ${ }^{\circ} \mathrm{C}$ & 9,0 \\
\hline 9 & Temperatur wet- bulb udara,${ }^{\circ} \mathrm{C}$ & 28,0 \\
\hline 10 & Karakteristik menara $($ KaV/L $)$ & 1,838 \\
\hline 11 & Laju penguapan, $\mathrm{kg} / \mathrm{s}$ & 5,3 \\
\hline 12 & Laju percikan $($ drift loss $), \mathrm{kg} / \mathrm{s}$ & 0,07 \\
\hline 13 & Laju blow-down, $\mathrm{kg} / \mathrm{s}$ & 1,35 \\
\hline 14 & Cyclus ratio $(\mathrm{CR}),-$ & 4,7 \\
\hline
\end{tabular}




\section{KESIMPULAN}

Desain proses sistem pendingin reaktor RRI-50 dan penentuan parameter-parameter operasinya berhasil dikerjakan, begitu pula telah diperoleh desain dasar pada komponen unitnya. Desain parameter operasi sistem pendingin ini didasarkan pada desain daya reaktor $50 \mathrm{MWtermal,} \mathrm{laju} \mathrm{aliran}$ massa pendingin dan temperatur pendingin dengan mempertimbangkan tuntutan aspek keselamatan teras reaktor sehingga temperatur pendingin masuk ke teras tidak lebih dari $44,5{ }^{\circ} \mathrm{C}$. Oleh karena itu pembuatan desain proses sistem pendingin menggunakan program ChemCad ini perlu ditetapkan dengan benar parameter operasi sistem pendingin tersebut yaitu temperatur, tekanan dan laju aliran massa pada setiap jalur pendingin. Adapun desain tangki tunda N-16, pompa sirkulasi, alat penukar panas dan menara pendingin adalah desain awal yang merupakan kelengkapan untuk menghasilkan suatu desain yang lebih konprehensif pada sistem pendingin utama RRI-50.

\section{DAFTAR PUSTAKA}

1. Sukmanto D, Ign. Djoko I., Analisis desain konseptual proses operasi sistem pendingin reaktor riset inovatif $20 \mathrm{MW}$ menggunakan paket ChemCAD, Prosiding PPI-PDIPTN PTAPB-Batan Yogyakarta 2013.

2. Iman K, Surian P, Tagor M.S. Desain teras alternatif untuk reaktor riset inovatif (RRI) dari aspek neutronik J. Tek. Reaktor. Nukl. Vol.16 no.1 Hal. 1-10; Feb. 2014.

3. Endiah P.H, Subekti M. Analisis aspek termohidrolika pada desain awal bahan bakar RRI daya tinggi. Prosiding seminar nasional TKPFN-19. Batan-UIN Sunan Kalijaga Yogyakarta, ISSN.0854.2910;10-2013.

4. $\quad$ PRSG-Batan. Sistem pendingin reaktor. LAK RSG-GAS Rev 10 Bab 6.vol.2. Jakarta;2010.

5. INVAP. Reactor cooling system and connected systems. RRRP-7225-SAR Chapt. 6. ANSTO;2004.

6. Heonil KIM, Hark Rho KIM, Kye Hong LEE, Ji Bok LEE. Design characteristics and startup tests of Hanaro, Journal of nuclear Science and Technology. vol.33. no.7. p.527-538; July 1996.

7. Onishi N. Diagram of primary cooling loop and heavy water cooling loop of JRR-3M. Kinds of a nuclear reactors - reactors for nuclear sciences and technologies. NSRA Japan; 2008.

8. Chemtation-Team. ChemCAD Version 6-User guide; 2011.

9. Christian BJ. The centrifugal pump - Structural and fluid mechanics. Grund for research and technology denmark; 2010.

10. Kern DQ. Process heat transfer. International student edition. Mc.Graw hill book co. $\mathrm{NY} ; 1965$.

11. Vera García. A simplified model for shell-and-tubes heat exchangers. Practical application. Applied thermal engineering 30. 1231-1241; 2010.

12. M. Lucas. Experimental determination of drift loss from a cooling tower with different drift eliminators using the chemical balance method. International journal of refrigeration 1779$178835 ; 2012$.

13. Mortaza Gholizadeh.The estimation of the cooling tower height by modeling the water and air contact situation in cooling tower falling film. Journal of chemical engineering and materials science.v.2(2). pp.21-27; February 2011.

14. Perry RH-Green DW. Psychrometry, evaporative cooling and solids drying. Sect. 12. Chemical engineer handbook. $6^{\text {th }}$ edition. The mcGraw-hill companies, Inc.Copyright $\odot$; 1999.

15. Viska M. Practical engineering guidelines for processing plant solutions. Cooling tower selection. Sizing (Engineering design guideline), KLM techn. group Malaysia;07-2011. 
16. Sukmanto D, Surip W. Analisis desain tangki tunda N-16 sistem pendingin RRI melalui aplikasi Relap5. Seminar nasional TKPFN-19 Yogyakarta; 09-2013.

17. Sukmanto D, Bambang H.G. Perhitungan desain termal penukar panas sistem pendingin RRI-50. Majalah ilmiah sigma epsilon; 2014 (draft rev.0).

18. Sukmanto D. Penentuan laju blow-down sistem menara pendingin RSG-GAS. Prosiding presentasi ilmiah penelitian dasar ilmu pengetahuan dan teknologi nuklir P3TM Batan Yogyakarta; 2003.

19. FrenchCreek. Cooling water modeling (WaterCycle-Rx). FrenchCreek softwarev.7; 2011. 